\title{
Sustainability of an Urban Forest: Bukit Timah Nature Reserve, Singapore
}

\author{
Kalyani Chatterjea \\ National Institute of Education \\ Nanyang Technological University \\ Singapore
}

\section{Introduction}

Singapore, an island republic, is situated south of the Malay Peninsula, between $1^{\circ} 09^{\prime} \mathrm{N}$ and $1^{\circ} 29^{\prime} \mathrm{N}$ and longitudes $103^{\circ} 38^{\prime} \mathrm{E}$ and $104^{\circ} 06^{\prime} \mathrm{E}$. The main island and 60 small islets cover an area of about $710.2 \mathrm{sq} \mathrm{km}$ and support a humid tropical type of vegetation. At the time of the founding of modern Singapore in 1819, practically the whole of the main island was forest covered. Land clearance for development was done in massive scale during the colonial times. After the first forest reserves were set up in 1883, efforts to conserve parts of the forested areas have evolved. In 1951 legal protection was given to Bukit Timah, Pandan, Labrador and the water catchment areas. When Singapore became an independent state in1965, there were five nature reserves in all (Wee \& Corlett, 1986). Since its independence in 1965, in an effort to develop its economy and infrastructure, Singapore has continued to clear forests to provide land for industries, residential use, military purposes, and infrastructure. With one of the highest population densities in the world, pressure on land is the driving force that has influenced the extents of the forests. But Singapore has managed to provide legal protection to retain some land as reserve forests. Till the 90 's nature conservation was a mere governmental task to maintain the forested areas of the island. About $4.5 \%$ of the total land area is given to forests and there are a total of four protected nature reserves in Singapore. Of these, Bukit Timah Nature Reserve and Central Water Catchment Reserve are the inland tropical rainforests, with some interior areas of primary rainforest. Protected under the Parks and Trees Act of 2005 for the protection of the native biodiversity, a total area of 3,043 ha is given to these two forests which were contiguous till 1995. Since then a six-lane highway cut through the heart of the forest, segregating Bukit Timah from its much bigger counterpart, into a 164 ha of some secondary and some primary forest. The actual closed forest covers only 75 ha of this. Though small, it is recorded as having 1000 species of flowering plants, 10,000 species of beetles, and many other organisms and does retain an authentic 'feel' of a primeval rainforest in the interiors. The forest is a mixture of lowland and coastal hill dipterocarp forest and some secondary forest, lying on the flanks of the highest $(163.6 \mathrm{~m})$, mostly granitic hill in Singapore. It is only $12 \mathrm{kms}$ away from the city centre and is surrounded by a fast-growing condominium belt of Singapore. Tagged as the country's flagship nature reserve, Bukit Timah represents the constant struggle and compromise between increasing pressures of urbanization and the commitment towards nature conservation currently faced by all countries. 
Expanding populations, increased income and leisure time, altered consumer demands, increasing media and commercial propaganda of nature-based attractions, higher awareness of Nature and natural landscapes, increasing interests in non-urban environments and off-the-beaten track places, as well as proliferation of urban lifestyles (Dotzenko et al., 1967; Poon, 1990; Sutherland et al., 2001) in the past decade have seen a rapid rise in the interest in Nature areas. Whether for a piece of Nature or to satisfy the adventurous, nature areas have become common destinations for people during their leisure times. This evolution of tastes has produced growing pressures on natural landscapes, adversely affecting the natural habitat conditions and causing degradation. Visits to remote forests have seen an unprecedented rise as conducted and organized tours to remote areas, sometimes even with comfortable facilities, have allowed otherwise sedate travelers to choose these Nature areas over other choices as their preferred destinations. Large-scale outdoor recreation leads to greater and more widespread ecological impacts on natural ecosystems (Lynn \& Brown, 2003) and forests near urban centres have been the worst affected, as these are seen as places of relaxation and physical exercise by increasing number of urban dwellers.

Being close to home, these urban forests also are visited on a regular basis and hence, the impact to such natural sites is more protracted. This paper discusses the case of Bukit Timah Nature Reserve, the 75 ha of partly primary and partly secondary low land Dipterocarp forest, located alongside the popular condominium belt in central Singapore and which is frequented by an unprecedented number of people from the nearby residential areas. The forest has been accorded protection by law as a gazetted Nature Reserve. As for the interiors, the forest in question is crisscrossed by a network of walking trails and the increased popularity of this forest has led to severe degradation of some of the trails. At the outer boundaries, the forest is getting encircled by the ever-encroaching urban residential and infrastructural developments, altering the peripheral environment and steepening the environmental gradients from forest boundaries to the interiors. As for its patrons, the visitor numbers have gone staggeringly high over the decades when the forest came to be more popular. The service demands of this clientele have also seen a distinct transformation and forest management, so far, has focused on keeping up with popular demands by providing various people-friendly facilities and amenities. Bukit Timah Nature Reserve, therefore, exemplifies the aspirations of nature conservation, as well as nature usage and exploitation that many other forested areas near urban developments may go through. Sustainability of such areas depend greatly on the analysis of the issues involved and assessment of the extent of problems brought about by such invasion from urban development.

\section{Methodology for the study}

Sustainability of BTNR is impacted upon by many factors, such as the increasing numbers of urban development around the forest and its resultant edge effects, the rising numbers of forest visitors and their impact on the forest interiors, the perceptions of the urban visitors who shape the forests' future through public participation. This study looks at these issues and analyses (i) the encroachment from non-forested urban development that impacts the forest peripheral environment (ii) the physical impacts of the heavy usage in the forest interiors, and (iii) the perceptions of stakeholders towards this remnant forest that may well influence the future sustainability of the forest.Forest peripheral environment was assessed 
by measuring the ambient temperature, and relative humidity along the forest boundaries, skirting the urban landuse such as the residential developments and the roads around the forest. Data was then mapped using GIS to ascertain the environmental gradient resulting from edge effects of the development.

To quantify the impact of hiking, jogging on soil properties, a post-impact sampling framework was employed, covering forest, trail, and trail-side segments along the forest paths. Following park-designated hiking trails, measurements were taken along transects through forest, trail and trail-sides, mostly at regular $100 \mathrm{~m}$ intervals. The results were then compared with adjoining undisturbed forested slopes (used as a control), to ascertain the degree of compaction and other changes trails and trail-side sites have gone through.

Visitors to the forest are an increasingly important factor in determining the future sustainability of the forest. Hence, apart from getting data on visitors visiting the forest, their profiles, usage preferences, surveys were also conducted to assess the perceptions these people have about the forest, its value as a nature reserve, and its services as a nature reserve. It is thought that such perceptions among the public users of the forest may well influence the sustainability of the forest.

\section{Background and site details}

Bukit Timah Nature Reserve (BTNR) is the only primary rainforest in Singapore, housing innumerable species of tropical trees and animals, of which a number are in the endangered list. Originally part of the much larger Central Water Catchment area, this forest was truncated from the bigger part of the forest in 1985 when the six-lane Bukit Timah Expressway (BKE) was constructed to run right through the heart of the forest. In addition to the expressway, currently there are more roads around the forest. As a result BTNR is physically fragmented, permanently severed from the bigger counterpart.

Presently the Nature Reserve has a designated size of some 164 ha of land area although the real forest is only about 75 hectares. In spite of the non-urban landscape around the forest, parts of the inner forest still maintain its primeval characteristics (Fig. 1) and offer the urban population much respite from the stresses of city life.

A metalled road (not open to vehicular traffic) runs up to the summit, while $10.6 \mathrm{kms}$ of dirt trails, often paved with rocks, concrete steps, or even wooden boardwalks criss-cross the forest, over steep slopes, and rocky surfaces. In addition to these, there are mountain biking trails $(6 \mathrm{kms})$ that offer varying degrees of challenge to bikers across steep and rough slopes. The forest interior has small streams and caves that are in the more remote areas and some parts are kept off from visitors by not having trails running through them. These interiors still show characteristics of undisturbed primary rainforest. The forest itself is quite dense with close canopy cover, complete with tall trees, heavy growth of lianas and epiphytes, middle and lower shrub layers with abundant supply of fresh ground litter. Studies on geomorphological processes in the past (Chatterjea, 1989a, b) recorded slow movement of surface sediments and a well-balance sediment budget on the well-drained forest floors of Bukit Timah, providing adequate nutrients to the dense vegetation and support to the forest slopes. Till the 1980s and early 1990s the forest was an unknown natural landscape, visited only by researching scientists, and occasional visitors who came there either for intellectual pursuits or to enjoy the aesthetic appeal of an undisturbed forested environment. 


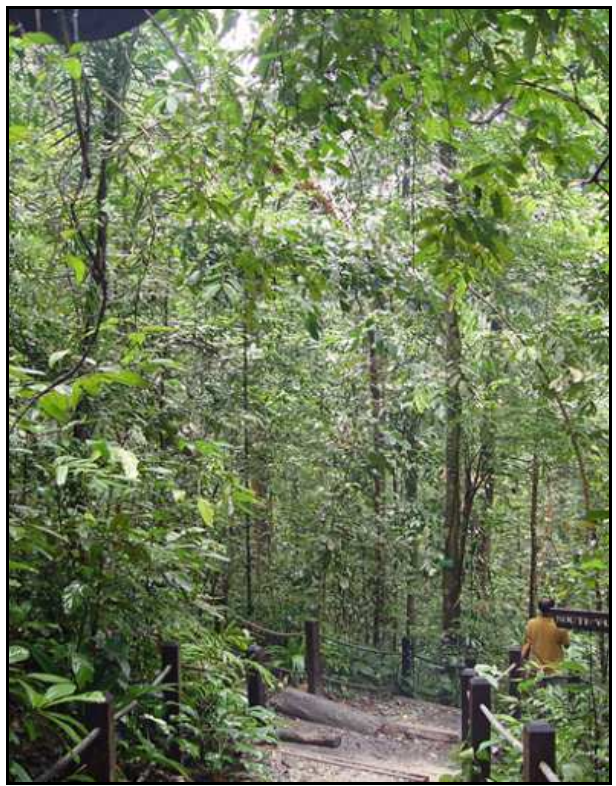

Fig. 1. The forest interior, with a walking trail

This close-to-nature status, however, attracted the attention of urban developers who targeted this location to cater to the home choices of an increasingly prosperous and more discerning local population who preferred to be close to nature as a respite from their hectic urban lifestyle. The urban land use plan of Singapore demarcated areas around BTNR for private residential development and soon condominiums filled up the area. In land-starved Singapore this newly-available proximity to Nature created opportunities for private land developers to develop residential properties very close to the Reserve, just outside the officially designated boundary of the forest. Several high-rise and low-rise condominiums have been developed even within 200 meter periphery of the forest (Fig. 2).

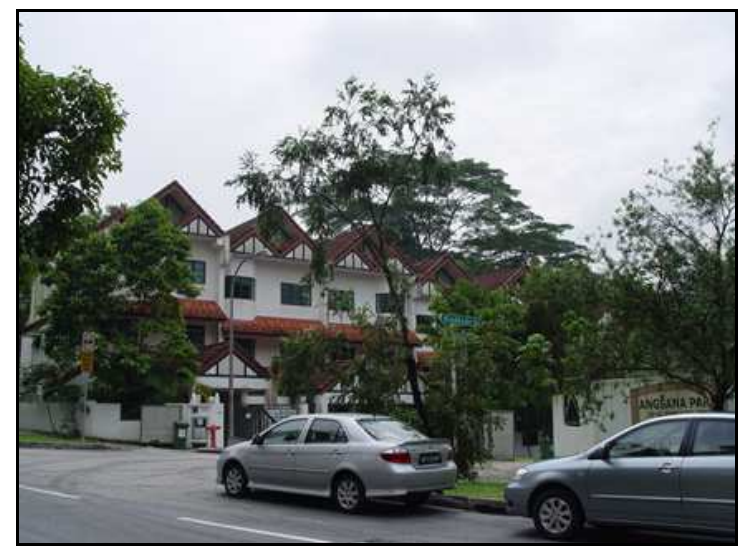

Fig. 2. One of the condominiums just outside the forest 
Figure 3 shows the land use of the areas around the forest in 1951, with open forest and fruit trees scattered with some low-impact residential development. At this time the only infringement was the railway line and one major road on one side of the forest. Figure 4, based on land use of 2009 however, shows how the urban development has encroached upon the outer boundaries and how transport infrastructure has kept pace with that.

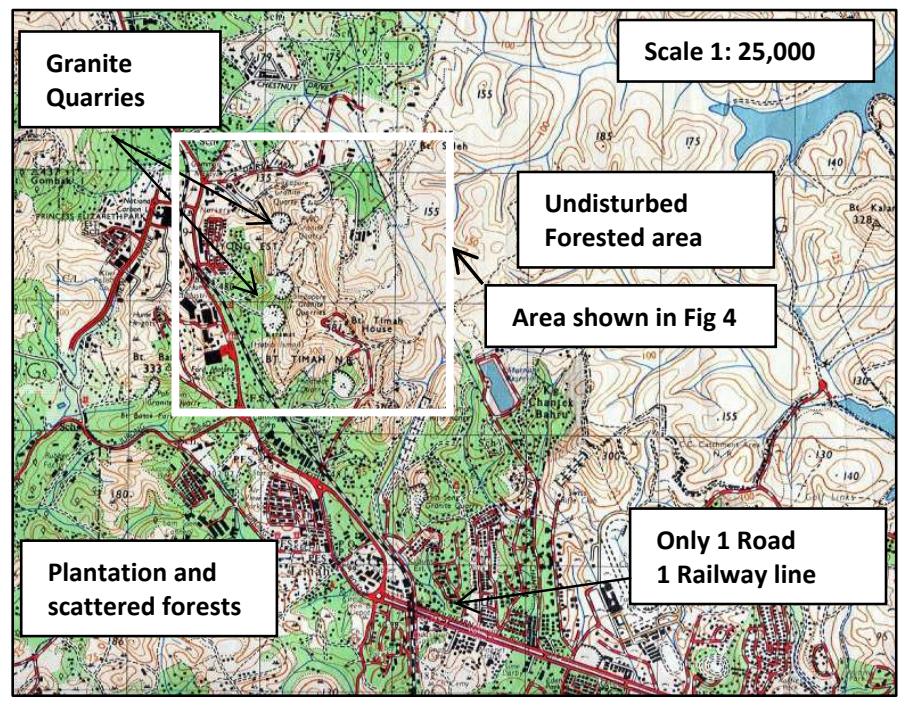

(Adapted from Topographical Map of Singapore, 1951)

Fig. 3. Land use around BTNR in 1951

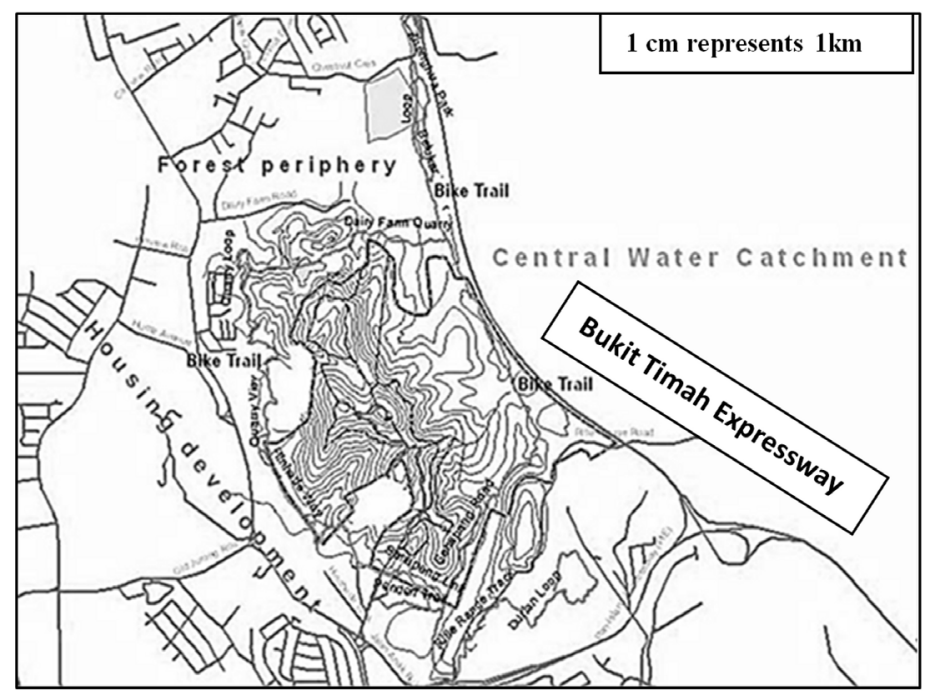

Fig. 4. Land use in 2009 (Based on author's survey): Area covered marked in Fig. 3 
The 1990s saw the rapid development of the residential areas and Fig. 5 shows the numbers of such development, all within a $2 \mathrm{~km}$ radius, which may be considered a walking distance from the forest. Residential development in such close proximity invariably lures the city dwellers and the natural environment of the forest is always a point of attraction, much advertised by the developers. From one condominium in 1984 with 157 residents near this forest, 2009 saw 24 condominiums and more than 21,000 residents, all within a short walking distance away from the forest boundaries (Fig.5) and the number is increasing with two very big developments launched in 2011 barely 300 meters away from the forest.

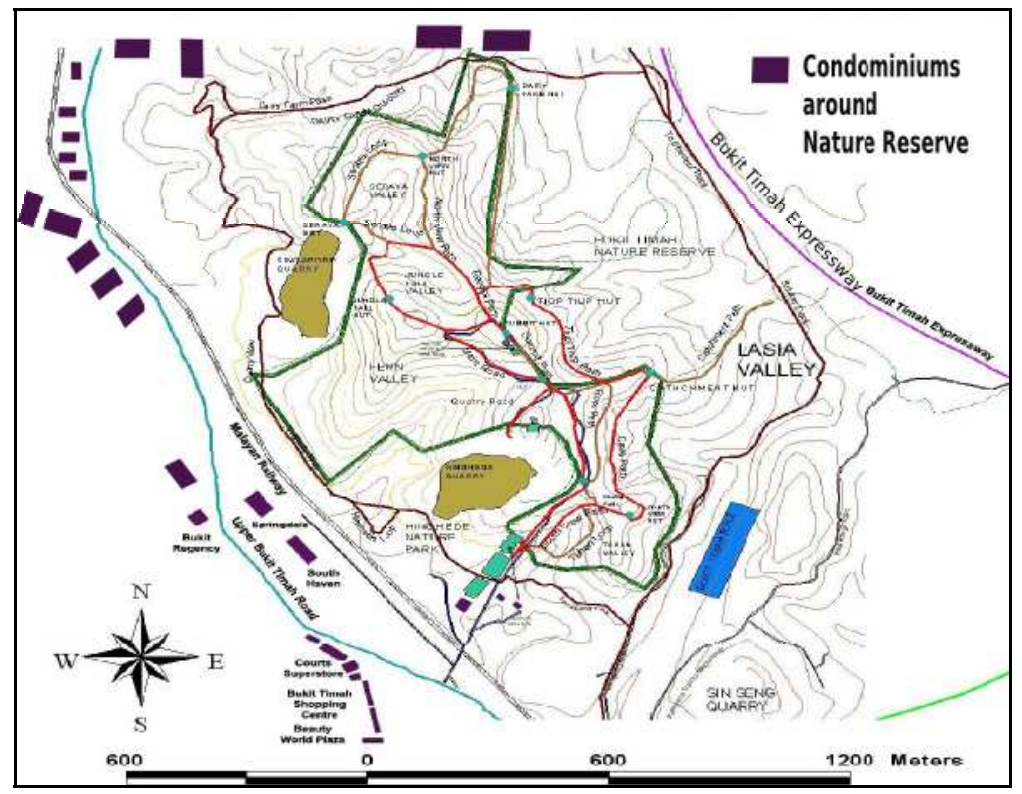

Fig. 5. Residential development within $2 \mathrm{~km}$ of BTNR

The forest boundaries also have urban infrastructural set-ups such as major roads, a railway line, a rifle range and even a golf course around it. 1985 saw the opening of a six-lane highway connecting the northern parts of the island with the rest, running through the dense forested areas of the Central Water Catchment, literally severing all forested connections between the bigger forests of the catchment with the now truncated BTNR (Fig. 4). So while the urban infrastructural growth connected the island's north and south, the island's most significant forest reserve got fragmented. BTNR now resides as a truncated urban forest, full of original wilderness properties that attract large numbers of newly-aware visitors to the interiors but is ill-placed to handle such large degree of impact.

\section{Effects of high density residential development}

\subsection{Impact on the forest peripheries and forest interiors}

Figure 6 shows the temperature differences between the forest peripheries and the forest interiors, while Fig. 7 shows the differences in relative humidity in the same locations. 


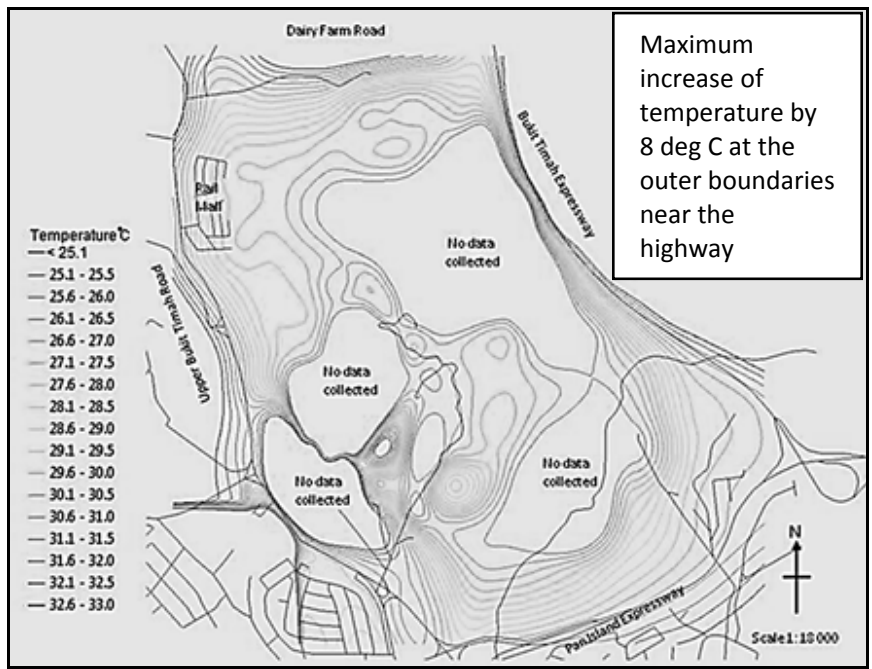

Fig. 6. Isotherms showing distribution of temperature in and around BTNR

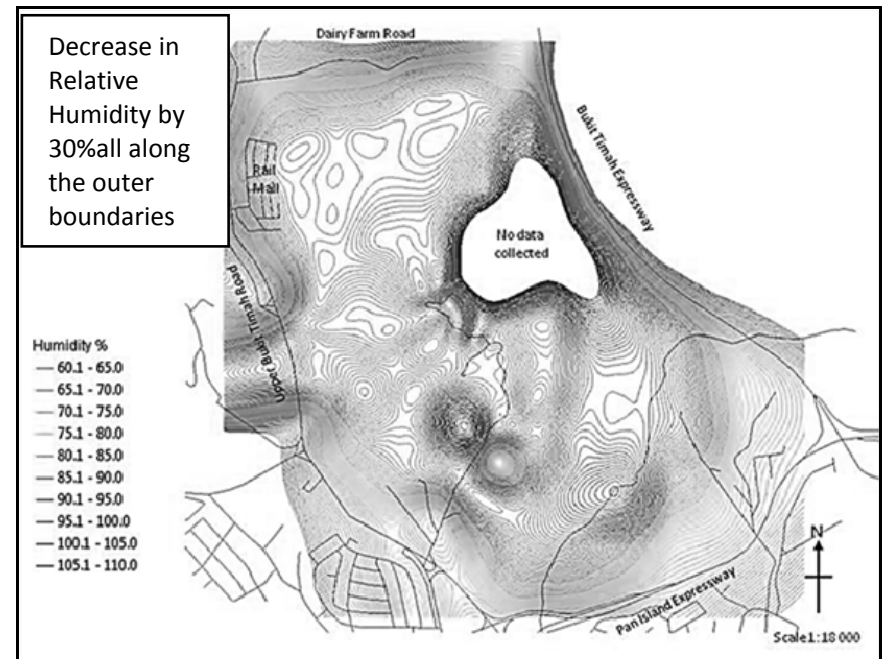

Fig. 7. Isohumes showing distribution of Relative Humidity in and around BTNR

From the data obtained from 162 locations reveal that there is a sharp increase in temperature by $8 \mathrm{deg} C$ in the outer boundaries and that the gradients are very steep in some locations, such as the areas skirting the Bukit Timah Expressway (BKE) as well as along the Dairy Farm Road, another dual-carriageway. Gradient is particularly steep all along the BKE -BTNR interface, with temperature increase of 8 deg C within $50 \mathrm{~m}$ at the edge of the forest from $25 \mathrm{deg} C$ to $33 \mathrm{deg}$ C. Similar effects are felt for relative humidity. Along the boundaries there has been a recorded drop of $40 \%$ in the humidity levels along the BKE-BTNR interface within a horizontal distance of $70 \mathrm{~m}$. Along the Dairy Farm Road 
average relative humidity drop was recorded to be about $30 \%$ all along the outside boundary. The slightly lower value recorded along the Dairy Farm Road is thought to be because of the presence of more trees along the outer boundaries of the forest and also because of some planted trees along the roadside. This is not the case along BKE, where the forest ends abruptly at the expressway. All data show clearly that the boundary environment is very different from the inner forest and the outer peripheries of this small forest are subjected to much harsher environment than the forest interior, creating a steep edge: interior difference. This is obviously detrimental to the well-being of the forest vegetation in particular and the entire forest ecosystem in general.

\subsection{Impact on forest visitor arrivals}

Apart from the other impacts from such urban landscape, residential developments close to the forest boundaries do provide a heavy visitor base to the forest. Figure 8, based on data released by the forest management shows the unprecedented rise in the number of visitors to the forest in recent years and numbers are increasing.

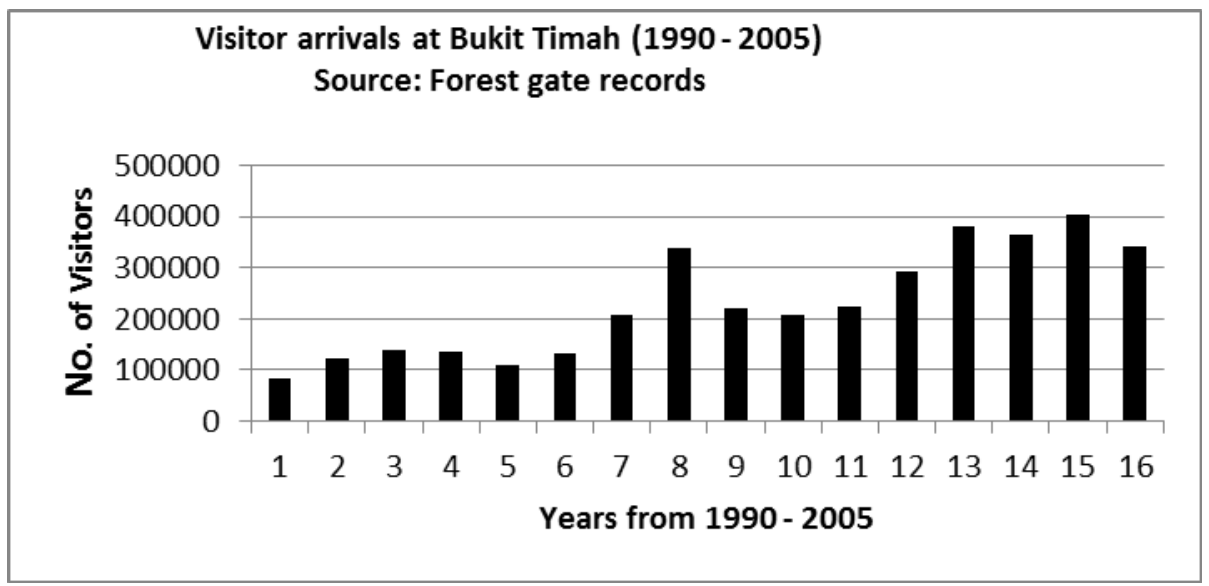

Fig. 8. Increase in number of visitors to BTNR (1990-2007): Overall percentage increase in annual number of visitors from 1990 to $2005>400 \%$

The figures, however, are only from records maintained on the visitor arrivals at the main gate. It needs to be mentioned here that BTNR has six other entrances where no records can be maintained because of the open access to those places. Therefore, it can be safely assumed that the actual visitor numbers are much higher than is seen in the official records. It is clear that the forest is a popular recreation getaway for the nature-loving urban dwellers, most of whom are local residents. Visitor surveys were done with 850 persons in total in 2004 and again in 2006 (Table 1).

The 2004 data showed that $68 \%$ preferred the trails, while $8 \%$ had no clear preference, though they often frequented the trails. This could well mean that these visitors also visited the trails, making the figure a staggering 76\%. The 2006 survey revealed similar but increasing trend of people visiting the trails, a possible $83-92 \%$ of the total visitors. With annual figures going as high as 402621 persons (2004), there are more than 1103 visitors per day and with $83 \%$ going to the trails, the $10.6 \mathrm{~km}$ walking trails alone would see a staggering 
figure of $>915$ visitors per day. This amounts to $>86$ persons trampling for around 2 hours per $\mathrm{km}$ of the trails, which is alarmingly high. While in $2004,46 \%$ percent had visited most of the trails, the 2006 survey revealed that at least $92 \%$ had ventured into at least one or more of the walking trails; $78 \%$ said they stay for two or more hours at each visit in 2004 while in 2006 surveys revealed that $83 \%$ of the visitors spend 1-2 hours in the forest..

\begin{tabular}{|c|c|c|c|c|}
\hline $\begin{array}{l}\text { Type of } \\
\text { observation }\end{array}$ & $\begin{array}{l}\text { Categories } \\
\text { surveyed }\end{array}$ & 2004 & 2006 & Comments \\
\hline \multirow{3}{*}{$\begin{array}{l}\text { Frequency of } \\
\text { visit in a year }\end{array}$} & $>10$ times & $31 \%$ & $64 \%$ & \multirow{3}{*}{$\begin{array}{l}\text { There has been a drastic } \\
\text { increase in the frequency of } \\
\text { visits }\end{array}$} \\
\hline & $3-10$ times & $39 \%$ & $25 \%$ & \\
\hline & $1-2$ times & $30 \%$ & $11 \%$ & \\
\hline \multirow{3}{*}{$\begin{array}{l}\text { Length of each } \\
\text { visit }\end{array}$} & $>2$ hours & $17 \%$ & $16 \%$ & \multirow{3}{*}{$\begin{array}{l}\text { Many people are staying in } \\
\text { the forest for a shorter time }\end{array}$} \\
\hline & 2 hours & $61 \%$ & $42 \%$ & \\
\hline & 1 hour & $22 \%$ & $42 \%$ & \\
\hline \multirow[t]{3}{*}{$\begin{array}{l}\text { Destinations } \\
\text { within the forest }\end{array}$} & Main Road & $24 \%$ & $17 \%$ & \multirow[t]{3}{*}{$\begin{array}{l}\text { Percentage of people visiting } \\
\text { trails might have gone up }\end{array}$} \\
\hline & Trails & $68 \%$ & $60 \%$ & \\
\hline & No Preference & $8 \%$ & $23 \%$ & \\
\hline \multirow{2}{*}{$\begin{array}{l}\text { Favourite } \\
\text { activities while } \\
\text { in the forest }\end{array}$} & $\begin{array}{l}\text { Nature Watch } \\
\text { (bird watching) }\end{array}$ & $19 \%$ & $11 \%$ & \multirow{2}{*}{$\begin{array}{l}\text { Solitary activities have seen } \\
\text { a decline } \\
\text { Exercise activities on the rise }\end{array}$} \\
\hline & $\begin{array}{l}\text { Jogging, exercise, } \\
\text { walking }\end{array}$ & $81 \%$ & $89 \%$ & \\
\hline
\end{tabular}

Table 1. Results of surveys done for visitors to BTNR $(n=850)$

The more revealing information relating to altered usage of the forest comes from the 2006 data which show that $89 \%$ of the visitors visit the forest for exercise, trail walk, jogging, and biking, with only $11 \%$ of the visitors having nature and bird watching in their mind. It is quite obvious that over the years BTNR is seen more as an exercise spot than as an area for quite appreciation of Nature.

\subsubsection{Impact of high visitor arrivals}

In response to this rising demand for nearness to Nature, Forest managers usually respond with more inroads into the forest and more alluring facilities, which unfortunately, not only take more number of visitors to the interiors, but also allow them to stay longer in the forest. Research shows that the fastest growing recreational activities are associated with forest trail use (Lynn \& Brown, 2003) as visitors use these inroads to venture into the remote wild, which may otherwise be non-passable. In BTNR, $84 \%$ of the visitors stay for 1-2 hours and all that time are spent on the trails. Trail degradation is established as one of the most evident consequences of expanding visitor numbers in nature parks. While trails are intended to confine visitors to predetermined paths and, thereby, minimize the negative impacts of human visits, additions to the trail network are an inevitable response to the increased movement of people within the forest.

Trampling on trails by increasing number of visitors alters the soil surface characteristics, mechanical properties and hydrophysical behavior. Severe compaction of the top surface leads to greater trail-surface erosion and changes in the forest floor environment, with top 
soil washed out, tree roots exposed, litter protection removed, and very importantly, compacting the soil beyond root penetration. Over time, the concentration of such activities on pre-defined trails result in extensive surface degradation and wildlife habitat disruption. This reduces the quality of wilderness experience of the visitors, in addition to degradation of the forest environment. As the recreational value of nature trails grows with public engagement in outdoor activities (Bhuju \& Ohsawa, 1998), park managers are faced with the dilemma of satisfying demands for opportunities of experiencing Nature from the growing number of visitors and the progressively deteriorating trails. Extensions of trail lengths have been the usual response to reduce impact per length of the trail. However, with the increasing number of visitors, this does not seem to ameliorate the problem but further impact the forest by taking visitors more and more into the forest interiors. Research has also established that trails are not only heavily used, but also widened through overuse, thus degrading the immediate peripheries of the trails as well (Chatterjea, 2007). With mainly recreational use of the forest, as Sutherland et al. (2001) suggest, it is important to examine the impact of recreational hiking on soil hydro-physical characteristics as well as to identify indicators of trail degradation so that the data can be used by land managers to assess the degree of stress imposed by recreational impacts.

Measured values of penetration resistance and shear strength, infiltration rate (Gardner and Chong, 1990) of the top surface soil can be analysed to show how increase in trail use leads to increased surface soil compaction and thus alters the original forest surface hydrological characteristics. Chatterjea (2007) gives details of the trail degradation and provides spatial information on hazardous trail segments which can be used by the forest management to target their repair works to affected sites as well as to plan future repairs, depending on requirements. Data regarding trail degradation along the well-used forest paths in BTNR are compared with the original undisturbed forest surfaces (Table 2). Impact of the heavy use is most obvious in the altered surface compaction. Readings of surface penetration resistance at 406 locations on all trails show alarming rise, as seen in Table 2 below.

\begin{tabular}{|c|c|c|c|}
\hline Surface Resistance & Forest & Trail & Trail-side \\
\hline Maximum Resistance $(\mathrm{kPa})$ & 965.3 & 2068.4 & 2137.4 \\
\hline Minimum Resistance $(\mathrm{kPa})$ & 68.9 & 137.9 & 68.9 \\
\hline Mean Resistance $(\mathrm{kPa})$ & 419.2 & 1238.8 & 912.0 \\
\hline
\end{tabular}

Table 2. Average Surface Penetration Resistance values, indicating surface compaction on trails in BTNR (From 406 locations)

Some trails such as Seraya Loop, being closer to one of the accessible boundary paths, has been widened beyond $3.5 \mathrm{~m}$ and illustrates how the trails develop severely compacted surfaces, give rise to ready surface wash during frequent rainstorms, wash off the top soil on the trail as well as from the surrounding slopes, become extremely slippery and hence highly hazardous. Surface compactions from two severely degraded trail segments are shown in Fig. 9 and Table 3. They show the differences in surface compaction on trails and undisturbed forest slopes, to illustrate the changes brought about by excessive use of the trails by visitors. 


\begin{tabular}{|c|c|c|c|c|c|}
\hline Location & Forest & Trail & $\begin{array}{l}\text { Root } \\
\text { Steps }\end{array}$ & $\begin{array}{l}\text { Trail- } \\
\text { side }\end{array}$ & Comments \\
\hline Seraya Loop: Site1 & 689.4 & 1323.7 & 1613.2 & 861.75 & \multirow{7}{*}{$\begin{array}{l}\text { - In this section, there is } \\
\text { room for straying } \\
\text { on the side of the } \\
\text { trail } \\
\text { - The trail has many } \\
\text { bike tread marks } \\
\text { and deep grooves } \\
\text { - The mean width of } \\
\text { this section of the } \\
\text { trail is } 3.4 \mathrm{~m}\end{array}$} \\
\hline Seraya Loop: Site2 & 103.4 & 1116.8 & 1654.6 & 689.4 & \\
\hline Seraya Loop: Site3 & 386.1 & 2171.6 & 2668.0 & 930.7 & \\
\hline Seraya Loop: Site4 & 344.7 & 1034.1 & 1964.8 & 758.3 & \\
\hline Seraya Loop: Site5 & 344.7 & 1447.7 & 1778.7 & 896.2 & \\
\hline Seraya Loop: Site6 & 137.8 & 792.8 & 1916.5 & 654.9 & \\
\hline Seraya Loop: Site7 & 193.0 & 2344.0 & 1379.0 & 978.9 & \\
\hline $\begin{array}{c}\text { Dairy Farm Loop: } \\
\text { Site1 }\end{array}$ & 322.0 & 1623.5 & 1814.2 & 761.8 & \multirow{7}{*}{$\begin{array}{l}\text { - This section of the trail } \\
\text { is very steep - in } \\
\text { places }>35 \mathrm{deg} \\
\text { - The trail has many } \\
\text { exposed rocks, tree } \\
\text { roots, and pot holes } \\
\text { - The trail has very } \\
\text { limited room on } \\
\text { the side for } \\
\text { sideways extension }\end{array}$} \\
\hline $\begin{array}{l}\text { Dairy Farm Loop: } \\
\text { Site2 }\end{array}$ & 104.4 & 2116.8 & 2655.0 & 859.4 & \\
\hline $\begin{array}{c}\text { Dairy Farm Loop: } \\
\text { Site3 }\end{array}$ & 295.1 & 1971.6 & 2668.0 & 980.0 & \\
\hline $\begin{array}{l}\text { Dairy Farm Loop: } \\
\text { Site4 }\end{array}$ & 231.7 & 1641.1 & 2660.3 & 758.8 & \\
\hline $\begin{array}{c}\text { Dairy Farm Loop: } \\
\text { Site5 }\end{array}$ & 244.4 & 2400.7 & 2195.7 & 996.0 & \\
\hline $\begin{array}{c}\text { Dairy Farm Loop: } \\
\text { Site6 }\end{array}$ & 136.8 & 1752.8 & 2016.5 & 723.9 & \\
\hline $\begin{array}{c}\text { Dairy Farm Loop: } \\
\text { Site7 }\end{array}$ & 153.0 & 2405.0 & 1878.0 & 1578.9 & \\
\hline
\end{tabular}

Table 3. Mean Penetration resistance values $(\mathrm{kPa})$ of surface soils on forest, trail, trail-side and root steps in Bukit Timah Nature Reserve

Due to excessive compaction, as shown in the surface penetration data, such trails go beyond repair, disallowing any root penetration, even after being left unused for some length of time. What is alarming is not just the degradation of the demarcated trails, but the increasing penetration data obtained from the trail-sides. These tracts running along the designated trails are initially covered often with indigenous ground vegetation, young saplings and fresh leaf litter, a major source of nutrients to the forest vegetation. With very high human traffic on the trails, visitors tend to go beyond the designated trails and this problem is exaggerated during heavy rains when the trails, with their compacted surfaces 


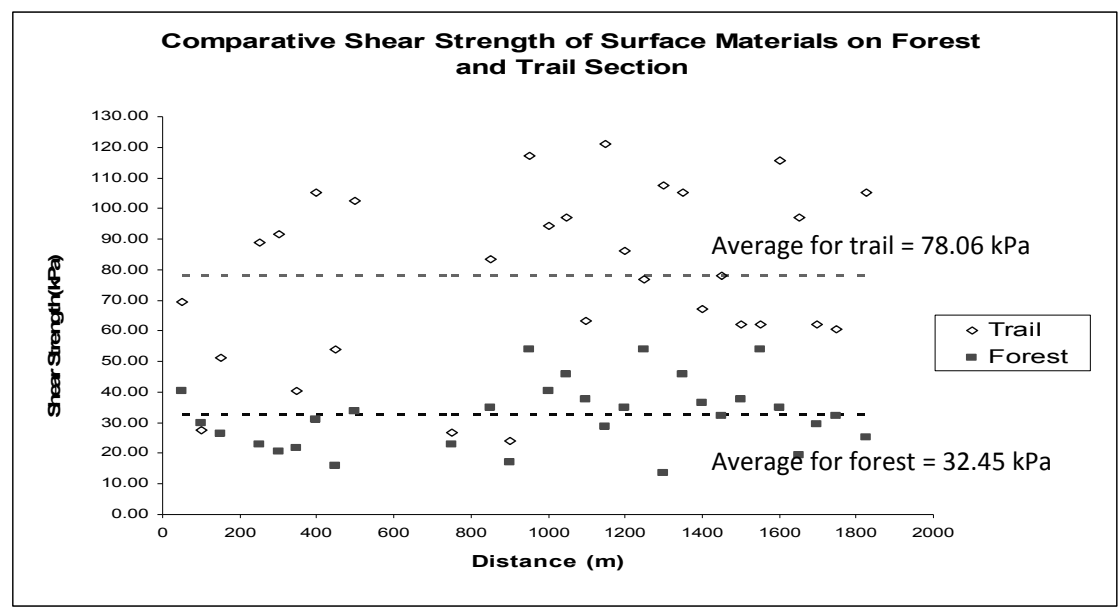

Fig. 9. Comparative Shear Strength of surface materials on different surfaces, indicating compaction: higher shear strength indicates greater compaction

are sites of heavy surfacewash. Top surfaces get muddy and subsequently the slippery surfaces are avoided by the joggers. This leads to widening of the existing trails. Fig.10 shows the width of one of the trails in BTNR, as measured and there is a marked increase in the width in all of the trails from the original layout of $0.5 \mathrm{~m}$.

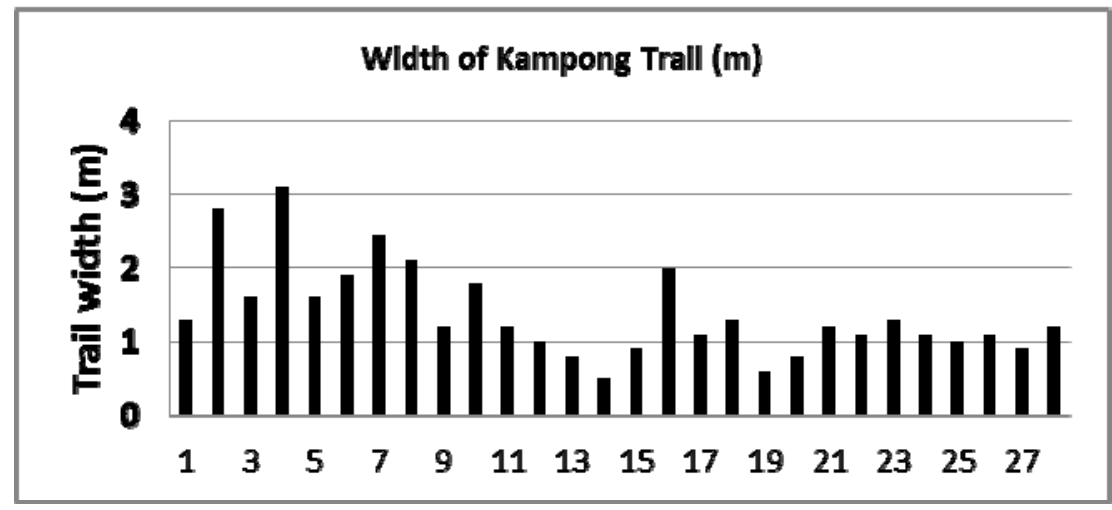

Fig. 10. Width of trail along Kampong Trail, a newly laid out trail at BTNR: $x 6$ increase in some sections

With prolonged impact on the trails, many of the trail segments are ridden with rills, pot holes, exposed tree roots, exposed and lose rock fragments, and smoothened soil surfaces (Fig. 11). Trails with such severe surface degradation and high surface compaction lead to permanent damage to the forest floors, inhibiting further root generation and extension. Plant saplings along the trail-sides often get smothered as trails are extended beyond the original layout. This impact, therefore, is extended to the immediate forest interiors.

Many trails get entrenched with bike tire treads and thus assist in channelizing the developed surface wash (Fig.11). Such damages cannot be easily repaired as trails are 
heavily used every day, leaving little time for natural regeneration or management intervention. Figure above shows the spatial extent of one of the damaged trail sections in BTNR and even newer trails such as Kampong Trail are not spared with rapid degradation subsequent to the opening up for public use. As these trails run through much of the forest interiors, trail degradation can be seen as a cause for concern as far as the health and sustainability of the forest is concerned.
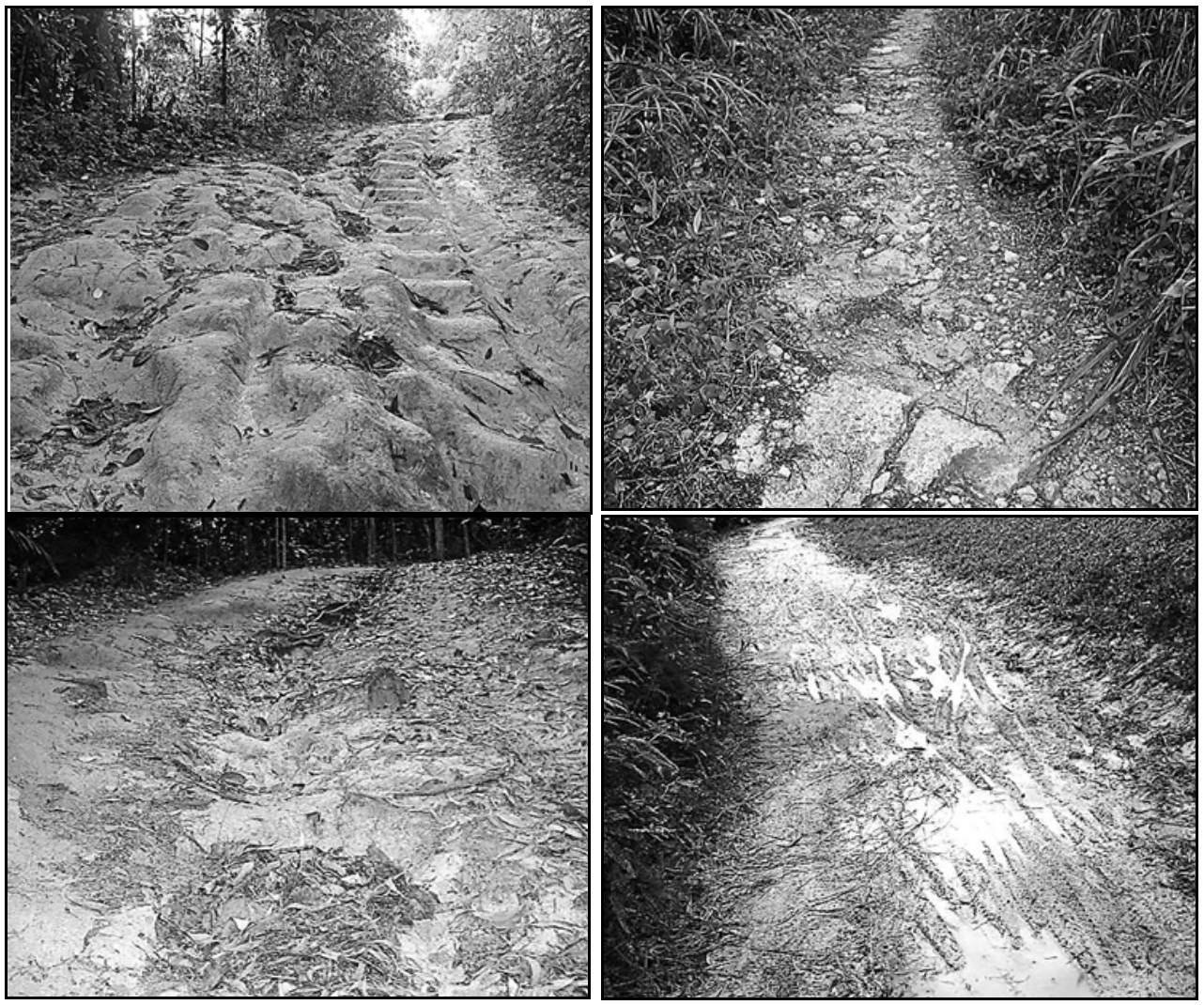

Fig. 11. Surface degradation along trails

\section{BTNR in the eyes of the visitors: Perceptions and views of stakeholders}

As the forest became increasingly popular to the local visitors, it became increasingly clear that the views, perspectives of the visitors drive the way this forest is managed. With initiatives from the National Parks Board which manages the forest, the forest has gone through some major facelift in terms of facilities aimed at attracting visitors and it sees large numbers of visitors, mostly locals from the neighbourhood and organized groups from schools and other organizations. It also provides opportunities for local schools, universities and other research bodies to conduct forest ecology related research. The forest has therefore moved from an unknown forest to one that provides services such as recreation, education, and research opportunities. 
To understand how this new involvement of the people and the continuous efforts to provide various services affects people's perception of the forest, surveys were conducted with 284 visitors in 2010. Table 4 gives a summary of the views received from the visitors about several aspects related to the forest.

\begin{tabular}{|l|c|}
\hline \multicolumn{1}{|c|}{ Views and perceptions } & $\begin{array}{c}\text { Percentage of people } \\
\text { interviewed (n=284) }\end{array}$ \\
\hline Unfazed by development around the forest & 43 \\
\hline $\begin{array}{l}\text { Thought urban development too close to the forest was } \\
\text { inevitable, given the shortage of land }\end{array}$ & 51 \\
\hline Against development close to the forest & 6 \\
\hline Supported idea of restricting visitors & 0 \\
\hline Supported idea of paid entrance & 0 \\
\hline Wanted more car parks & 100 \\
\hline Those who said trails should be repaired & 40 \\
\hline Those who said trails should be left as it is & 24 \\
\hline Those who didn't notice the degradation of trails & 36 \\
\hline Those who said the forest was too crowded but was inevitable & 53 \\
\hline Those who said the forest was not too crowded & 47 \\
\hline
\end{tabular}

Table 4. Views and perceptions of visitors to BTNR $(n=284)$

The survey reveals the opinions of an urban population, whose outdoor pursuits do not allow any room for consideration for Nature conservation. Although a fair number of people mentioned that they value coming to the forest as it brings them closer to Nature, they do not see the urgent need to ensure that this piece of forest is conserved for what it is. Most people are comfortable to use it as a Nature Park that gives them a respite from urban stresses and yet they do value it as a piece of Nature.

\section{Conclusion and comments}

While BTNR falls under IUCN (World Conservation Union) Category IV and is classed as a Habitat/Species Management Area (Protected Area managed mainly for conservation through management intervention) (Australian Government Department of the Environment and Heritage, 2006; IUCN, 2006), its activities also include public participation whether for recreation or education. This dual role thrust on the forest, as a nature area as well as one for recreational and educational use has provided a greater responsibility on the park management, and the issue of survival of the forest environment in the face of rocketing interests in the forest and its natural environment has become a big challenge for environmental conservation in this urban forest remnant. Efforts of the forest management so far has been to offer varieties of activities for different age groups and inclinations and many of the trails have been covered with board walks and efforts have been taken to blend the additional features to the forest environment. In response to demands from educational institutions, the forest now houses an Education Centre at the western boundary that allows schools to hold field classes (Fig. 12). Hindhede Park with its rest houses, viewing platform overlooking the scenic quarry lake is another example of the forest management to divert the pressure of visitors from the real forest interiors. Currently there are strict rules regarding groups visiting the forest in large numbers and these are subject to prior approval but individual or small groups are exempt from such restrictions. Forest management also does trail management and trail maintenance, as and when necessary, using indigenous 
forest resources to blend with the environment. But such efforts are mostly ad-hoc and not done in a regular planned manner.
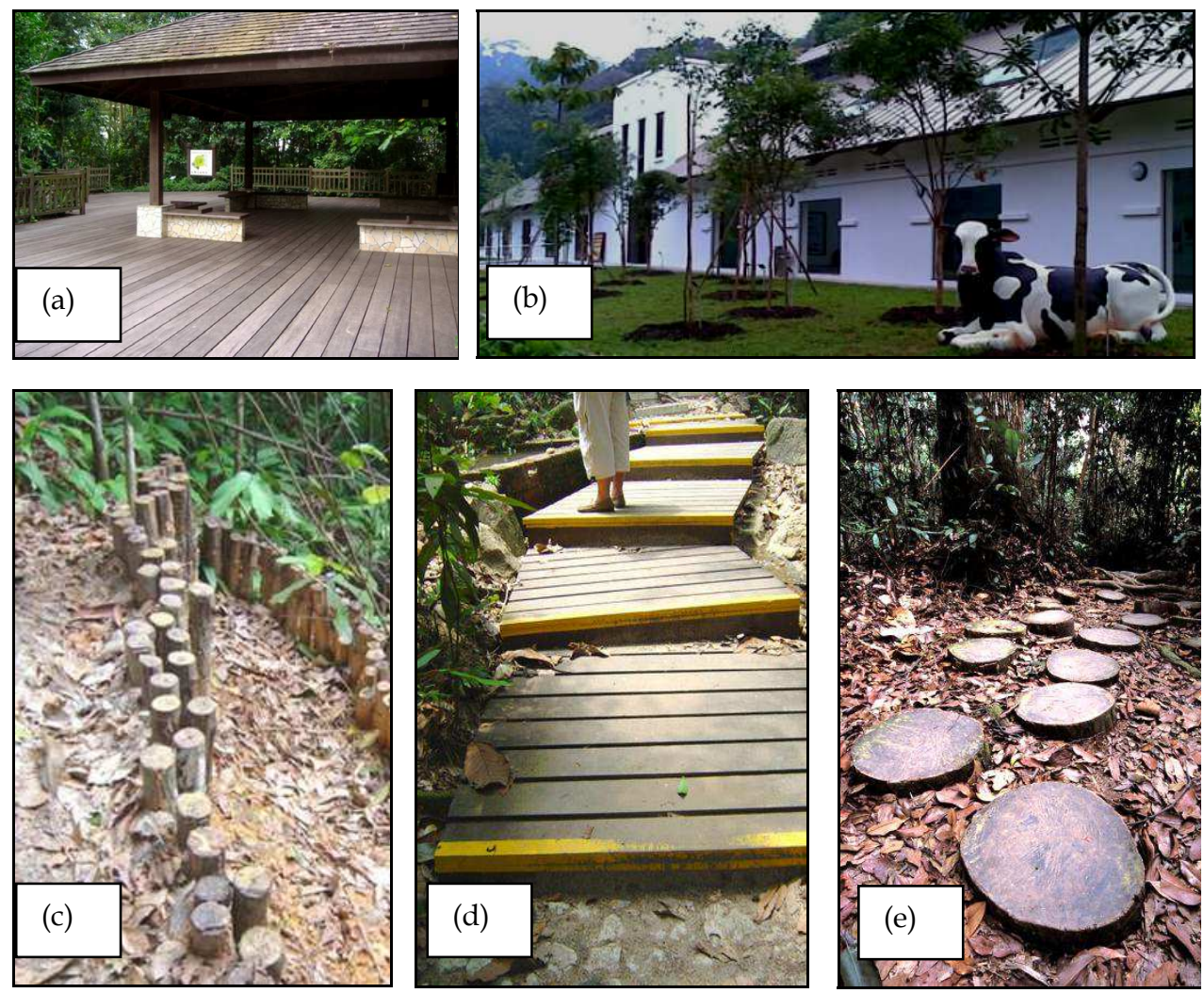

Fig. 12. Initiatives taken by the forest management in response to changing usage of the forest: (a) Rest Huts, (b) Education Centre, (c), (d), and (e) Trail management

However, as surveys suggest, rugged trails still seem to be the best attraction of this forest and $89 \%$ of the visitors go directly to the trails. New trails of all grades and gradients have been laid out through the forest to cater to the growing demand. One such example is the Kampong Trail which actually links BTNR to the next forest in the Central Water Catchment, the MacRitchie forest. Currently there are various networks of trails through varying gradients of the forest, running through small streams, caves, rock outcrops, dense vegetated slopes and deserted old hutments, giving the much desired rustic and wild environment that urban dwellers crave for during their leisure times.

With annual figures going as high as 402621 persons, the $10.6 \mathrm{~km}$ walking trails alone would see a staggering 1103 visitors per day. This figure is not final as entrees from the six unguarded entrances are not included in this data. If the IUCN guidelines of 10 persons per hectare per day are followed, the 164 ha area of BTNR should be able to support a visitor figure of 1640 per day (World Tourism Organization, 1999). But the 75 ha closed forested area of BTNR that is actually visited by people can only support an optimum visitor number 
of only 750 per day. If the present visitor preferences for the trail $(92 \%)$ are considered, the trails should only get a daily maximum of 690 visitors. The present figures (an estimated minimum of 1103 persons, not including the ones who come to the forest through the unmanned entrances) are markedly higher than this optimum value. As mentioned earlier, the trails do show the impact of such intensive usage.

When forest patches are under stress from overuse, the forest managers have basically two choices: (1) maintenance of trails with the help of engineering structures such as board walks, surface layering with forest/ artificial materials to ensure that the trails are in usable condition even under severe use, (2) controlling the number of visitors to the area. However the strategy of controlling the visitors is never seen as an acceptable alternative for two reasons. The forests are considered as nature areas for the recreation and enjoyment of the public. Any restrictions on their use may be seen as infringement on public rights. Restrictions also keep the public away from the problem, creating a forced avoidance and a possible apathy, which goes against the grain of conservation of public forest areas.

Surveys conducted for this research revealed that visitors to Bukit Timah Nature Reserve do not advocate regulating the number of visitors, although some do mention having restrictions on times to reduce the total number of visitors (Table 4). But, quite contrary to what John and Pang (2004) found out in Hong Kong, visitors to BTNR recorded their concerns for the forest and actually mentioned that the natural environment must be conserved, although they were not sure how. So the public sentiment towards conservation of this forest reserve is positive. Surveys show visitors opting for a combination of all types of management - but are reluctant to accept closing down of trails. Judging from the visitor responses collated for this study, the more acceptable way towards a managed forest is through close monitoring and response through management of the conditions, rather than restricting the visitorship. Therefore, choices left to the park managers have to focus on managing the existing forest paths with the given resources.

Although this forest trail management is generally left to the forest/ park managers, little institutional effort is made towards actually ensuring that it is done in an organized manner. Trail maintenance in many forests is left to the users and other voluntary organizations. While there are many guidelines on trail maintenance, trail layouts (U.S.D.A. Forest Service, 1991; Florida Trail Association, 1991), an effective management, especially in small forest reserves requires an organized schedule and planning based on site specific surveys and location-specific decisions. In the absence of organized scientific support and database, most of the maintenance is dependent on visual surveys by the rangers and is at best an ad hoc attempt to maintain an area under stress from overuse. While vast wildernesses have the resilience to bounce back from stressful conditions, if left to do so, smaller patches of nature around urban areas, such as BTNR, are the ones that are more vulnerable and are in danger of being reduced to degraded lands, especially if proactive measures are not emplaced to monitor the changes in the conditions.

With urban centres on the rise and populations and their lifestyles going through changes with the times, such dwindling nature pockets need to be brought to focus in order to sustain them even in the face of rapid intrusions from urban development. One of the recent notable developments is this growing acceptance for the need to assess and possibly reduce the impacts on nature areas for conserving these pockets of nature in and around urban areas. Assessment of the impacts, demarcation of the stress indicators, identification of the options to improve, prioritizing the amelioration, reducing or avoidance of the causes of threats and hazards are some of the issues that need to be stressed upon, if nature areas are to be conserved, either in big wilderness areas or in places near urban developments. As 
Barrow (2006) mentions, environmental risk management incorporates estimation of risk, evaluation of risk and also includes response to risk. Hence, it is imperative that the lay-out of forest trails, regular monitoring of their condition, and their maintenance are carried out in a planned manner by the park managers to benefit the visitor and at the same time reduce the impacts of trail use.

While forests of all dimensions are subject to degradation due to increasing influx of visitors, it is the urban forest patches in close proximity of populated urban centres that are more at risk of such intensive usage and consequent degradation. Developing some longterm monitoring and management protocols, regular monitoring and updating of trail conditions, and constant alignment of usage and amelioration of its impacts are essential for long term sustainable use of the forest located close to urban areas.

At Bukit Timah, while urban development is already at stone's throw from the forest boundaries and this cannot be reverted, it is imperative that any further urban encroachment is kept at bay, through development of a conscientious public view and a committed governmental effort targeted towards long-term conservation of this forest patch. One workable plan could be achieved through managed and well-placed diversion of visitor traffic from the core of the forest by building forest corridors for people yearning leisure activities in green spaces. Several sites may be possible, such as connecting the nearby Bukit Batok Nature Park with the existing Bukit Timah Nature Reserve through building of a walking green corridor across one of the busy roads (Upper Bukit Timah Road). Similarly, the recently vacated Malayan Railway line that skirts BTNR can easily be used as not just a green corridor but also an effective diversion for visitor traffic directly from the main gate of BTNR, thus relieving BTNR from the strangling pressure of visitors. The popularity of the recently vacated railway line proves that it may prove successful. Public education regarding sustainability of BTNR is also essential to maintain the status of the forest as a nature reserve. The current thrusts of the forest management through some public talks, in-forest posters need to reinforced and involvement of NGOs such a Nature Society of Singapore needs to be more targeted if this effort is to be sustained.

Bukit Timah Nature Reserve, for its size, its rich diversity, its services to the local population, its vulnerability in the face of growing urbanization is a forest that is a case for concern. Issue of sustainability of forests has never been as acute as it is in the case of Bukit Timah Nature Reserve.

\section{Acknowledgements}

Part of this research on the forest environment was funded by a project on Trail Degradation at Bukit Timah Nature Reserve, NIE RP 19/02 KC. Many of the ground data could not have been collected without the help of students from various courses at National Institute of Education, Nanyang Technological University, Singapore. Support from National Parks Board, Singapore and help offered by the officers at Bukit Timah Nature Reserve for conducting this research are acknowledged. Visitors to the forest who helped by giving their views are also acknowledged.

\section{References}

Australian Government Department of the Environment and Heritage. (2006). Six IUCN Protected Area Categories, In: IUCN category of reserve, 02-03-2006, Available from: http://www.deh.gov.au/parks/iucn.html\#IV 
Barrow, C. (2006). Environmental Management for Sustainable Development: Principles and Practice (2nd Edition), Routledge, ISBN-10: 041536535X, London.

Bhuju, D.R. \& Ohsawa, M. (1998). Effects of Nature Trails on Ground Vegetation \& Understorey Colonization of a Patchy Remnant Forest in an Urban Domain. Biological Conservation, Vol. 85, No. 1-2, (July-August 1998), pp. (123-135), ISSN: 0006-3207.

Chatterjea, K. (1989). Surface Wash: The Dominant Geomorphic Process in the Surviving Rainforest of Singapore. Singapore Journal of Tropical Geography, Vol. 10, No. 2, (December 1990), pp. (95-109), ISSN: 0129-7619.

Chatterjea, K. (1994). Dynamics of Fluvial and Slope Processes in the Changing Geomorphic Environment of Singapore. Earth Surface Processes and Landforms, Vol. 19, No. 7, (November 1994), pp. (585-607), ISSN: 0197-9337.

Chatterjea, K. (2006). Public Use of Urban Forest, its Impact, and related Conservation Issues: The Singapore Experience, In: Challenging Sustainability: Urban Development and Change in Southeast Asia, Wong T.C. et al, pp. (53-79), Marshall Cavendish Academic, ISBN:13:978-981-210-307-9, Singapore.

Chatterjea, K. (2007). Assessment and Demarcation of Trail Degradation in a Nature Reserve, Using GIS: Case of Bukit Timah Nature Reserve. Land Degradation and Development, Vol. 18, No. 5, (September-October 2007) pp. (500-518), ISSN: 1085-3278.

Dotzenko A. D.; Papamichos N. T. \& Romine D. S. (1967). Effects of Recreational Use on Soil \& Moisture Conditions in Rocky Mountain National Park. Journal of Soil \& Water Conservation, Vol. 22, No. 5, (September-October 1967), pp. (196-197), ISSN: 0022-4561.

Florida Trail Association, Inc. (1991). Trail Manual of Florida Trail, Florida Trail Association, Gainsville, Florida, USA.

Forest Services, U.S. Department of Agriculture. (1991). Trails Management Handbook (amended: FSH 2309.18), Government Printing Office, Washington, D. C. (FSH 2309.18), Washington, D.C." Government Printing Office.

Gardner, B.D. \& Chong, S.K. (1990). Hydrological Responses of Compacted Forest Soils. Journal of Hydrology, Vol. 112, No. 3-4, (January 1990), pp. (327-334), ISSN: 0022-1694.

IUCN (World Conservation Union). (2006). Protection of Bukit Timah as a reserve, In: IUCN Management Category, 02-03-2006, Available from:

http://sea.unep-wcmc.org/sites/pa/0538v.htm

Lynn, N. A. \& Brown, R. D. (2003). Effects of Recreational Use Impacts on Hiking Experiences in Natural Areas. Landscape \& Urban Planning, Vol. 64, No. 1-2, (June 2003), pp. (77-87), ISSN: 0169-2046.

Poon, A. (1990). Competitive Strategies for a "New Tourism", In: Progress in Tourism, Recreation $\mathcal{E}$ Hospitality Management, Cooper, C. P., pp. (91-102), Belhaven Press, ISBN: 0471945099, London

Sutherland, R. A.; Bussen, J. O.; Plondke, D. L.; Evans, B. M. \& Ziegler, A. D (2001) Hydrophysical Degradation Associated With Hiking Trail Use: A Case Study of Hawai'iloa Ridge Trail, O'Ahu, Hawai'i. Land Degradation \& Development, Vol. 12, No. 1, (January-February 2001), pp. (71-86), ISSN: 1099-145X.

Wee, Y. C. \& Corlett, R. T. (1986). The City and the Forest: Plant Life in Urban Singapore, Singapore University Press, ISBN:9971691035, Singapore.

World Tourism Organization. (1999). Guide for local authorities on developing Sustainable Tourism, (Supplementary Volume on Asia and the Pacific), World Tourism Organization, ISBN: 9284402808, Madrid, Spain 


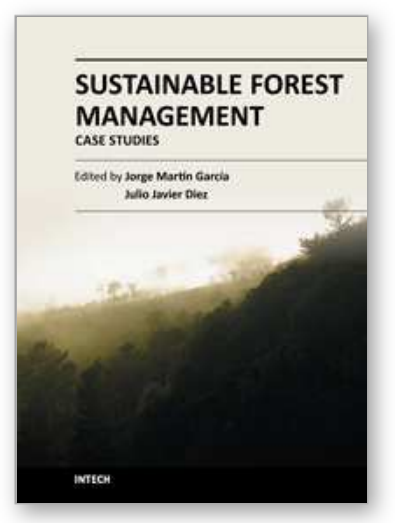

\author{
Sustainable Forest Management - Case Studies \\ Edited by Dr. Julio J. Diez
}

ISBN 978-953-51-0511-4

Hard cover, 258 pages

Publisher InTech

Published online 11, April, 2012

Published in print edition April, 2012

The concept of forest sustainability dates from centuries ago, although the understanding of sustainable forest management (SFM) as an instrument that harmonizes ecological and socio-economic concerns is relatively new. The change in perspective occurred at the beginning of the 1990s in response to an increased awareness of the deterioration of the environment, in particular of the alarming loss of forest resources. The book collects original case studies from 12 different countries in four continents (Africa, America, Asia and Europe). These studies represent a wide variation of experiences from developing and developed countries, and should clarify the current status of SFM worldwide and the problems associated with its implementation.

\title{
How to reference
}

In order to correctly reference this scholarly work, feel free to copy and paste the following:

Kalyani Chatterjea (2012). Sustainability of an Urban Forest: Bukit Timah Nature Reserve, Singapore, Sustainable Forest Management - Case Studies, Dr. Julio J. Diez (Ed.), ISBN: 978-953-51-0511-4, InTech, Available from: http://www.intechopen.com/books/sustainable-forest-management-case-studies/sustainabilityof-an-urban-forest-bukit-timah-nature-reserve-singapore

\section{INTECH}

open science | open minds

\section{InTech Europe}

University Campus STeP Ri Slavka Krautzeka 83/A 51000 Rijeka, Croatia Phone: +385 (51) 770447

Fax: +385 (51) 686166 www.intechopen.com

\section{InTech China}

Unit 405, Office Block, Hotel Equatorial Shanghai No.65, Yan An Road (West), Shanghai, 200040, China 中国上海市延安西路65号上海国际贵都大饭店办公楼405单元 Phone: +86-21-62489820

Fax: +86-21-62489821 
(C) 2012 The Author(s). Licensee IntechOpen. This is an open access article distributed under the terms of the Creative Commons Attribution 3.0 License, which permits unrestricted use, distribution, and reproduction in any medium, provided the original work is properly cited. 